\title{
Reducing Ventral Tegmental Dopamine D2 Receptor Expression Selectively Boosts Incentive Motivation
}

\author{
Johannes W de Jong', Theresia JM Roelofs', Frédérique MU Mol', Anne EJ Hillen', Katharina E Meijboom', \\ Mieneke CM Luijendijk', Harrie AM van der Eerden', Keith M Garner', Louk JMJ Vanderschuren ',2 and \\ Roger AH Adan*,I
}

'Brain Center Rudolf Magnus, Department of Translational Neuroscience, University Medical Center Utrecht, Utrecht, The Netherlands; ' 2 Division of Behavioural Neuroscience, Department of Animals in Science and Society, Faculty of Veterinary Medicine, Utrecht University, Utrecht, The Netherlands

\begin{abstract}
Altered mesolimbic dopamine signaling has been widely implicated in addictive behavior. For the most part, this work has focused on dopamine within the striatum, but there is emerging evidence for a role of the auto-inhibitory, somatodendritic dopamine D2 receptor (D2R) in the ventral tegmental area (VTA) in addiction. Thus, decreased midbrain D2R expression has been implicated in addiction in humans. Moreover, knockout of the gene encoding the D2R receptor (Drd2) in dopamine neurons has been shown to enhance the locomotor response to cocaine in mice. Therefore, we here tested the hypothesis that decreasing D2R expression in the VTA of adult rats, using shRNA knockdown, promotes addiction-like behavior in rats responding for cocaine or palatable food. Rats with decreased VTA D2R expression showed markedly increased motivation for both sucrose and cocaine under a progressive ratio schedule of reinforcement, but the acquisition or maintenance of cocaine self-administration were not affected. They also displayed enhanced cocaine-induced locomotor activity, but no change in basal locomotion. This robust increase in incentive motivation was behaviorally specific, as we did not observe any differences in fixed ratio responding, extinction responding, reinstatement or conditioned suppression of cocaine, and sucrose seeking. We conclude that VTA D2R knockdown results in increased incentive motivation, but does not directly promote other aspects of addiction-like behavior.
\end{abstract}

Neuropsychopharmacology (20I5) 40, 2085-2095; doi:I0.I038/npp.20I5.60; published online I April 20I5

\section{INTRODUCTION}

Both obesity and substance addiction are enormous socioeconomic and public health problems (European Commission, 2007; Gustavsson et al, 2011). Estimates are that 27 million people around the world are addicted to illicit drugs, and 76 million are addicted to alcohol (United Nations Office on Drugs and Crime, 2012). Indeed, substance addiction has been calculated to be the most financially costly of all major neuropsychiatric disorders (Effertz and Mann, 2013). Obesity prevalence is increasing and its comorbidities, ie, type 2 diabetes, cardiovascular disease, and cancer are a major cause of death in the western world (Flegal et al, 2010). Interestingly, it has been suggested that there is overlap in the neural and behavioral processes of these disorders, as addiction-like processes may underlie certain forms of obesity (Gearhardt and Corbin, 2009; Volkow et al, 2013; Potenza, 2014). Moreover, addictive behaviors have also been proposed to play a

*Correspondence: Professor RAH Adan, Department Translational Neuroscience, Brain Center Rudolf Magnus, University Medical Center Utrecht, STR.4.205, Universiteitweg 100, 3584 CG Utrecht, The Netherlands, Tel: +8875685 I7, E-mail: r.a.h.adan@umcutrecht.nl Received 2 December 2014; revised 23 February 2015; accepted 23 February 2015; accepted article preview online 4 March 2015 role in the psychopathology of eating disorders that do not necessarily lead to obesity such as bulimia nervosa and binge eating disorder (Kessler et al, 2013; Gearhardt et al, 2014).

All addictive substances directly or indirectly target the mesolimbic dopamine (DA) system (Di Chiara and Imperato, 1988; Nestler, 2005), and DA signaling has also been implicated in the (maladaptive) intake of palatable food (Baik, 2013; Meye and Adan, 2014). The cell bodies of the mesolimbic DA system are located within the midbrain ventral tegmental area (VTA). These DA neurons project throughout the forebrain, and the most dense projection reaches the ventral striatum (nucleus accumbens (NAcc) core, shell and olfactory tubercle). Five types of DA receptors have been identified. These can be divided into two classes: the DA receptor D1-like (D1 and D5) which activate adenylyl cyclase and the DA receptor D2-like (D2, D3 and D4) which have an inhibitory influence on this enzyme (Sibley and Monsma, 1992). Here, we focus on the DA D2 receptor (D2R) which is expressed post-synaptically on (among others) GABAergic medium spiny neurons in the striatum, as well as pre-synaptically and somatodentritically on DA neurons, where they act as auto-inhibitory receptors (Usiello et al, 2000). Stimulation of the D2R on midbrain DA neurons inhibits firing as well as DA production and release (Aghajanian and Bunney, 1977; Tepper et al, 1997; Anzalone et al, 2012). 
In the striatum, neurons expressing the $\mathrm{D} 2 \mathrm{R}$ are thought to work in concert with DA D1 receptor-expressing neurons to mediate action selection, salience, motivation, and incentive learning (Robinson and Berridge, 1993; Isomura et al, 2009; Salamone et al, 2009).

Both the pre- and post-synaptic D2R have been associated with addictive behavior. Decreased D2R availability in the striatum is associated with drug addiction and severe obesity (Wang et al, 2001; de Weijer et al, 2011; Volkow et al, 2011) (but see Eisenstein et al, 2013). Decreased somatodendritic D2R availability has recently been implicated in novelty seeking and impulsivity in humans (Zald et al, 2008; Buckholtz et al, 2010) and rodents (Tournier et al, 2013). These character traits have been associated with drug addiction (Jupp and Dalley, 2014) and obesity (Nederkoorn et al, 2007). The notion that somatodendritic D2R play a role in addictive behavior is also supported by animal studies. Thus, rats that exhibit enhanced cocaine self-administration show sub-sensitivity of D2 somatodendritic autoreceptors (Marinelli and White, 2000). Likewise, mice lacking the D2 autoreceptor display elevated DA release and are hypersensitive to the psychomotor effect of cocaine (Bello et al, 2011), and midbrain D2R downregulation has been shown to be involved in the effects of cocaine on plasticity of VTA glutamate signaling (Madhavan et al, 2013). In addition, amphetamine self-administration as well as prolonged exposure to cocaine results in decreased midbrain D2R sensitivity (Henry et al, 1989; Calipari et al, 2014b). Conversely, administration of the D2R agonist quinpirole into the VTA inhibits cocaine-induced reinstatement of cocaine seeking (Xue et al, 2011). Taken together, these data indicate that that decreased midbrain D2R availability promotes addictive behavior.

Previously, a DA cell-type-specific approach has been used to ablate the $\mathrm{D} 2 \mathrm{R}$ in DA neurons in mice. This resulted in an enhanced locomotor response to cocaine and increased motivation for sucrose (Bello et al, 2011). As this approach ablated the D2R in all midbrain DA neurons, it remains unclear whether these behavioral effects were mediated by altered function of DA neurons in the VTA or the substantia nigra. Furthermore, constitutive absence of the D2R throughout development may evoke compensatory functional adaptations. Here, we therefore opted for an shRNA-mediated approach to reduce the expression of the $\mathrm{D} 2 \mathrm{R}$ specifically in the VTA of adult animals. As previous experiments have suggested a role for decreased midbrain D2R availability in addiction, we hypothesized that the knockdown of VTA D2R promotes behaviors associated with addiction, ie, high motivation, resistance to punishment, and high vulnerability to relapse (see (Deroche-Gamonet et al, 2004)). First, we tested the psychomotor effect of a low dose of cocaine. Next, animals were trained to self-administer sucrose or cocaine, and we probed their motivation for sucrose or cocaine under a progressive ratio (PR) schedule of reinforcement. Subsequently, we investigated conditioned suppression as a model of compulsive cocaine seeking (Vanderschuren and Everitt, 2004). Last, we investigated the propensity of animals to reinstate sucrose or cocaine seeking after extinction by priming with sucrose, cocaine, or a cocaineassociated cue, as a model for relapse.

\section{MATERIALS AND METHODS}

\section{Animals}

Six-week-old male Wistar rats (Charles River, Sulzfeld, Germany) weighing 150-200 $\mathrm{g}$ at the start of the experiment were individually housed in makrolon cages $(37.8 \times 21.7 \times$ $18.0 \mathrm{~cm}$ ) under a reversed 12:12 light/dark cycle (lights on at $19: 00 \mathrm{~h}$ ). They had ad libitum access to chow and water and a wooden block was provided as home cage enrichment. All experiments were approved by the Animal Ethics Committee of Utrecht University and were conducted in agreement with Dutch laws (Wet op de Dierproeven, 1996) and European regulations (Guideline 86/609/EEC).

\section{Production of the D2R shRNA}

Four sequences were selected based on homology to Rat D2R mRNA (NM_012547.1). To prevent aspecific binding, we assessed the sequence using the NCBI Basic Local Alignment Search Tool. These were: 1: CATCGTCACTCTGCTGGTC TA, 2: CAACCTGAAGACACCACTCAA, 3: TGGTGGG TGAGTGGAAATTCA, and 4: AGGATTCACTGTGACAT CTTT. Hairpins were designed and cloned into an miR155based precursor, which was located in the first intron of enhanced green fluorescent protein (GFP) (Du et al, 2006). The construct containing enhanced GFP and the artificial pre-mRNA was then cloned into an AAV vector behind the enhanced synapsin promoter (White et al, 2011). In this way, the expression of the shRNA would be driven by RNA polymerase II. We opted for this strategy because U6 or H1 promoter-driven (polymerase II-mediated) shRNA expression has been shown to have toxic effects (van Gestel et al, 2014), which we do not observe using the current strategy. In the case of van Gestel et al (2014), damage was assessed by staining for tyrosine hydroxylase (TH) as well as for miR-124 using an LNA in situ hybridization procedure. We observed proper miR-124 and $\mathrm{TH}$ expression in animals injected with the D2R knockdown or the control vector. Ex vivo testing on a dual luciferase assay (Du et al, 2006) showed that sequence 2 and 3 resulted in the most efficient knockdown (Figure 1a). These two sequences were therefore selected for in vivo testing in a pilot experiment $(n=12)$, in which both altered the sensitivity to cocaine (see below). For the final experiments in this paper, we selected sequence 2 , as it showed a slightly larger effect in the pilot experiment. Animals injected with the D2R knockdown vector were compared with animals injected with a control vector of equal length that was targeted at a gene (luciferase) that does not have an equivalent in mammals. The sequence of the control shRNA was: AAAGCAATTGTTCAGGAACC.

\section{Surgery}

Rats were anesthetized with Hypnorm (0.315 mg/kg fentanyl, $10 \mathrm{mg} / \mathrm{kg}$ fluanisone intramuscular, Janssen Pharmaceutica, Beerse, Belgium) and supplemented with Hypnorm as needed. Rats allocated to cocaine self-administration experiments were implanted with a single intravenous catheter into the right jugular vein aimed at the left vena cava. Catheters (Camcaths, Cambridge, UK) consisted of a $22 \mathrm{~g}$ cannula attached to silastic tubing (0.012 ID) and fixed to nylon mesh. The mesh end of the catheter was sutured subcutaneously (s.c.) 

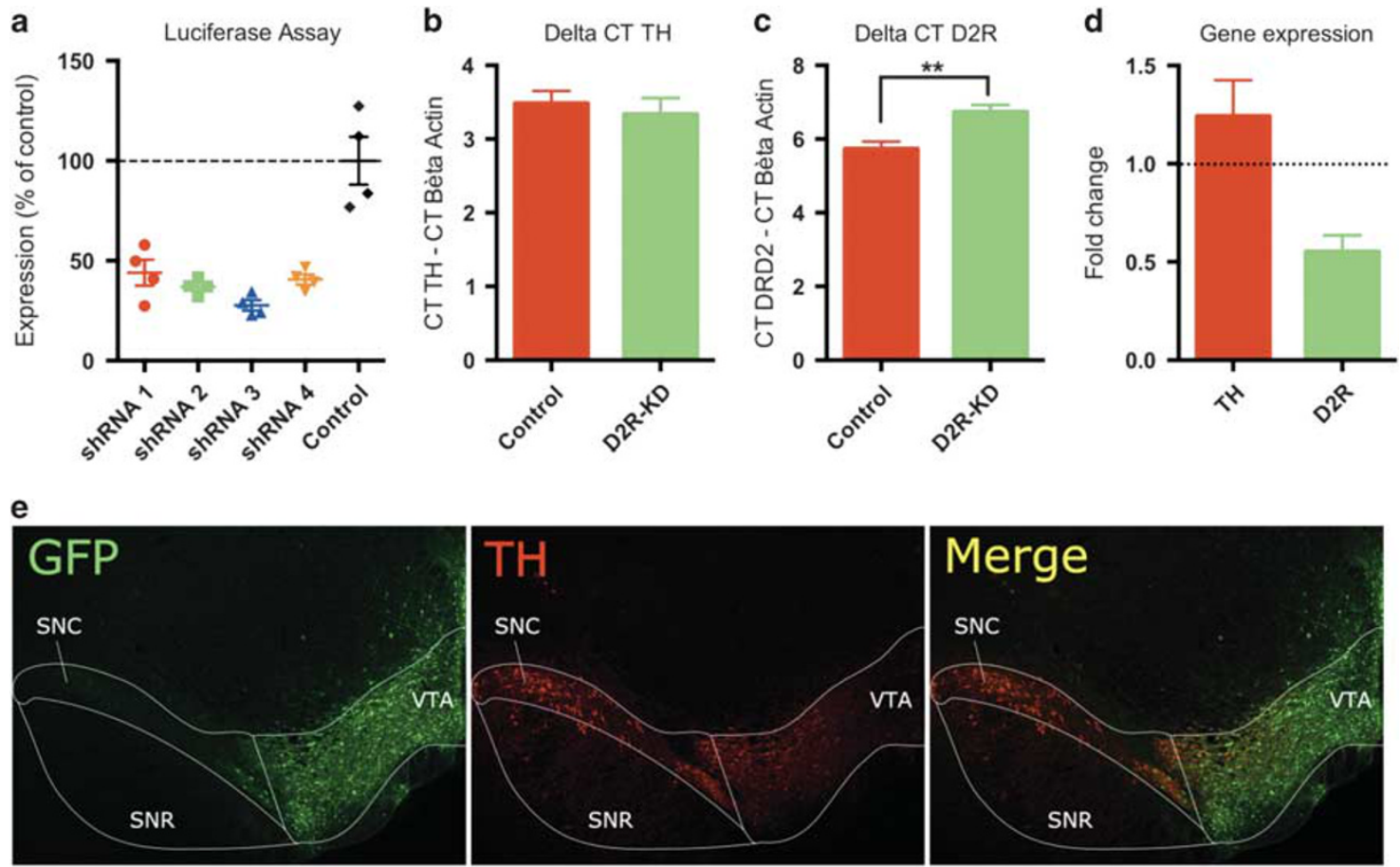

Figure I Virus expression and D2R knock down. (a) The expression of a D2R-Renilla luciferase fusion protein was assessed by measuring light emission following addition of the Renilla substrate, coelenterazine. All four constructs decreased light emission compared with a control hairpin. The data were corrected for transfection efficiency by co-transfection with firefly luciferase. (b) D2R and TH mRNA expression was assessed using qPCR in VTA dissections. No significant difference in $\Delta C T$ value for TH was observed in D2R knockdown animals vs controls. (c) $\Delta C T$ values for D2R mRNA were significantly increased in D2R knockdown animals compared with controls. (d) $\Delta \Delta C T$ values were used to calculate fold change compared with control for both TH and DRD2. We observed a decrease of about 50\% in D2R mRNA expression. (e) The location of virus expression was confirmed by staining the animals for GFP and TH. GFP expression in the substantia nigra was a criterion for exclusion, but this was not observed. SNC $=$ Substantia nigra pars compacta, $\mathrm{SNR}=$ Substantia nigra pars reticulata, $\mathrm{VTA}=$ Ventral tegmental area, D2R-KD $=\mathrm{D} 2 \mathrm{R}$ knockdown. Data represent mean $+\mathrm{SEM} * * \mathrm{*}<0.0 \mathrm{I}$.

on the dorsum. Next, the animals were placed in a stereotaxic apparatus (David Kopf), and $1 \mu \mathrm{l}$ of a solution containing AAV vector was injected bilaterally into the VTA (coordinates relative to bregma: anteroposterior -5.40 , mediolateral \pm 2.20 , dorsoventral -8.90). Carprofen $(50 \mathrm{mg} / \mathrm{kg}$, s.c. $)$ was administrated once before and twice after surgery. Gentamycin $(5 \mathrm{mg} / \mathrm{kg}$, s.c.) was administered before surgery and for 5 days post surgery. Animals were allowed 7-9 days to recover from surgery.

\section{Cocaine-Induced Locomotor Activity}

Locomotor activity was assessed as described previously (Veeneman et al, 2011). Animals were first habituated to the testing apparatus (plastic boxes measuring $50 \times 33 \times 40 \mathrm{~cm}$, $\mathrm{l} \times \mathrm{w} \times \mathrm{h}$ ). Horizontal locomotor activity was registered using a camera positioned approximately $2 \mathrm{~m}$ above the setup. The data were recorded and analyzed using a video tracking system (Ethovision, Noldus, Wageningen, the Netherlands). A session started with a 15 min habituation period. Next, the animals received an intraperitoneal (i.p.) injection of saline or cocaine (cocaine $\mathrm{HCl}$, Bufa BV, Uitgeest, the Netherlands; $5 \mathrm{mg} / \mathrm{kg}$ or $10 \mathrm{mg} / \mathrm{kg}$ dissolved in saline). Locomotor activity was measured for $30 \mathrm{~min}$. All locomotor experiments were performed during the light phase of the day/night cycle. The animals for this experiment were used for the sucrose self-administration experiments before testing for cocaine-induced locomotion, which was assessed 5 weeks after surgery.

\section{Operant Conditioning Apparatus}

Rats were trained in operant conditioning chambers $(30.5 \times$ $24.1 \times 21.0 \mathrm{~cm}$; Med Associates, St. Albans, VT, USA). The chambers were placed in light- and sound-attenuating cubicles equipped with a ventilation fan. Each chamber was equipped with two $4.8-\mathrm{cm}$-wide retractable levers, placed $11.7 \mathrm{~cm}$ apart and $6.0 \mathrm{~cm}$ from the grid floor. The assignment of the left and right lever as active and inactive lever (see below) was counterbalanced across rats. A cue light $(28 \mathrm{~V}, 100 \mathrm{~mA})$ was present above each lever and a house light $(28 \mathrm{~V}, 100 \mathrm{~mA})$ was located on the opposite wall. Sucrose pellets $(45 \mathrm{mg}$; 5TUL, TestDiet, USA) were delivered to a receptacle between the two levers. Cocaine infusions were controlled by an infusion pump (PHM-100-3-33; Med Associates) placed on top of the cubicles. During the cocaine self-administration sessions, polyethylene tubing ran from the syringe placed in the infusion pump via a swivel to the cannula on the subjects' back; in the operant chamber, tubing was shielded with a metal spring. Sucrose and cocaine self-administration experiments were conducted in identical chambers. The operant testing apparatus was controlled by MED-PC (version IV) Research Control \& Data Acquisition System software. 
Self-administration sessions were carried out once daily, between 9 AM and 6 PM, for 5-7 days a week.

\section{Sucrose Self-Administration}

Animals were trained to respond for sucrose as described previously (la Fleur et al, 2007). Operant sessions lasted $1 \mathrm{~h}$ during which the availability of the reward was signaled to the animal by illumination of the house light. Pressing the active lever resulted in the delivery of a sucrose pellet, the illumination of the cue light above the active lever for $5 \mathrm{~s}$ and retraction of the levers. After a 20-s time-out period, the levers were reintroduced and the house light illuminated, signaling the start of a new cycle. Pressing on the inactive lever was without scheduled consequences. Animals were trained to respond for sucrose under a fixed-ratio (FR) 1 schedule of reinforcement, meaning that each active lever press resulted in the delivery of one sucrose pellet $(45 \mathrm{mg})$. After acquisition of sucrose self-administration under this schedule, the response requirement was increased to five lever presses (ie, an FR5 schedule of reinforcement). Subsequently, we assessed the motivation for sucrose under a PR schedule of reinforcement, in which the response requirement was progressively increased after each obtained reward $(1,2,4,6,9,12,15,20,25$, etc.; Richardson and Roberts, 1996). A PR session ended after the animal failed to obtain a reward within $30 \mathrm{~min}$. In this experiment, we assessed FR and PR responding both before and after D2R knockdown; PR testing commenced 2 weeks after virus injection. After the final PR session (the animals received six sessions in total), animals received two more FR5 sessions before extinction. Extinction responding was assessed under identical circumstances as FR responding, except that responding on either lever was without scheduled consequences. Animals received 10 30-min extinction sessions followed by a reinstatement session that was identical to an extinction session, except that three sucrose pellets were delivered at the beginning of the session. All operant behavior for sucrose was assessed in the same cohort of animals $(n=23)$. During the experimental period, animals received ad libitum chow in the home cage.

\section{Cocaine Self-Administration}

A separate cohort of 37 rats was used for the cocaine selfadministration experiments. Cocaine self-administration experiments, conducted as previously described (Veeneman et al, 2012a; 2012b), started 2 weeks after surgery. Cocaine $\mathrm{HCl}$ (Bufa BV, Uitgeest, The Netherlands) was dissolved in saline. The first 2 weeks consisted of acquisition of selfadministration under an FR1 schedule of reinforcement, followed by 1 week of testing under a PR schedule of reinforcement (which occurred 4 weeks after virus injection). To assess the sensitivity of the animals to acquire cocaine self-administration, we used a unit dose $(0.083 \mathrm{mg} /$ infusion $)$ that was threefold lower than our usual training dose during the first five self-administration sessions, followed by five sessions in which our usual unit dose of cocaine was available, ie, $0.25 \mathrm{mg} /$ infusion (Baarendse et al, 2014). Selfadministration training started under a FR1 schedule of reinforcement, in which responding on the lever resulted in delivery of a cocaine infusion (16.7 $\mu \mathrm{l} / \mathrm{s}$, during $6 \mathrm{~s})$, retraction of the levers, and the illumination of a cue light above the active lever for $6 \mathrm{~s}$. This was followed by a 20-s time-out period during which the levers remained retracted and both the cue and house light were turned off. A new cycle was then started by insertion of the lever. These FR1 sessions lasted for $60 \mathrm{~min}$. After FR1 responding had stabilized (approximately 10 sessions), a PR schedule of reinforcement was introduced, in which the response requirement increased progressively after each obtained reward $(1,2,4,6,9,12,15$, 20, 25, etc.; Richardson and Roberts, 1996), and reward delivery was followed by a $10-\mathrm{min}$ time-out period to minimize the influence of cocaine-induced psychomotor effects on responding for the next infusion. Animals were tested for three PR sessions. Next, the animals were trained under a heterogeneous seeking-taking chain schedule of reinforcement (Olmstead et al, 2000; Vanderschuren and Everitt, 2004; Veeneman et al, 2012b; Limpens et al, 2014) with a random interval (RI) of $120 \mathrm{~s}$ on the seeking link (ST(RI-120)). These seeking-taking sessions started with the introduction of a new lever ('seeking lever') and the illumination of the house light. The first press on the seeking lever initiated the RI and pressing this lever was without consequences until the RI had elapsed. When the RI had elapsed, pressing the seeking lever resulted in retraction of the seeking lever and insertion of the taking lever. Next, responding on the taking lever (under the FR1 schedule of reinforcement) resulted in an infusion with cocaine, illumination of the cue light, retraction of the taking lever, and the switching-off of the house light. This was followed by a 10-min time-out period to minimize the influence of cocaine-induced psychomotor effects on responding for the next infusion. After the time-out period, a new cycle started with the reintroduction of the seeking lever and the illumination of the house light. When the rats had acquired the task under a RI of $2 \mathrm{~s}$, the RI was progressively increased between sessions until animals had acquired the task under an RI of $120 \mathrm{~s}$. The program automatically ended after $2 \mathrm{~h}$ or if animals had obtained 10 rewards, whichever occurred first. The conditioned suppression procedure consisted of a conditioning phase in which a subgroup of rats $(n=26$, 12 control and 14 D2R knockdown) learned to associate a $85 \mathrm{~dB}, 2900 \mathrm{~Hz}$ tone (CS) with footshock $(0.35 \mathrm{~mA}, 1 \mathrm{~s}, 20$ presentations) in a different environment, as described before (Vanderschuren and Everitt, 2004; Limpens et al, 2014). A control group of animals ( $n=7,4$ control and 3 D2R knockdown) was subjected to the same procedure but without the delivery of footshocks. Rats were then presented with the seeking lever in the operant-conditioning chamber. We assessed the amount of seeking lever responses made during seven 2-min blocks. Two-minute intervals in which the tone CS was presented (CS-ON interval) were alternated with 2-min intervals where the tone CS was absent (CS-OFF interval). The total number of lever presses made during presentation of the CS was taken as the outcome measure. Cocaine was not available during conditioned suppression sessions. Subsequently, the rats were exposed to daily $1-\mathrm{h}$ extinction sessions in which taking lever responses were without scheduled consequences. This continued until the rats made less than 30 responses for three consecutive days. We then assessed reinstatement following an i.p. injection of cocaine $(5-10 \mathrm{mg} / \mathrm{kg}$, i.p.) or following the presentation of the cocaine associated cue-light and retraction of the levers 
contingent with a response on the taking lever. After each 1 -h reinstatement session, rats received extinction sessions until they made less than 30 responses in a session.

\section{Tissue Preparation}

Animals were killed by i.p. injection of pentobarbital. For qPCR experiments, the brains were removed, quickly frozen on dry ice and stored at $-80^{\circ} \mathrm{C}$. For immunohistochemistry experiments, animals were given an intracardial perfusion with cold 4\%PFA in PBS. After dissection, the brains were post-fixed for $24 \mathrm{~h}$ in $4 \%$ PFA in PBS and then stored in $30 \%$ sucrose in $\mathrm{PBS}$ at $4{ }^{\circ} \mathrm{C}$ until ready for immunohistochemistry.

\section{Quantitative Polymerase Chain Reaction}

Fresh frozen brains were thawed in PBS and the VTA was quickly dissected and dissolved in Trizol (Invitrogen). RNA was obtained using phenol-chloroform extraction followed by ethanol precipitation. All samples were diluted to a concentration of $100 \mathrm{ng} / \mu \mathrm{l}, 1 \mu \mathrm{l}$ of which was used per qPCR measurement. qPCR was performed using QantiTect SYBR Green RT-PCR kit (QIAGEN) according to the manufacturer's instruction. The following primers were used: Drd2forward: CTGTGGCTGATCTTCTGGTG; Drd2-reverse: CACACGGTTCAGGATGCTT; beta-actin-forward: CGTTG ACATCCGTAAAGACC; beta-actin-reverse: TAGAGCCA CCAATCCACACA.

\section{Immunohistochemistry}

Perfused brains were cut at $40 \mu \mathrm{m}$ and stored in $30 \%$ sucrose and $0.02 \% \mathrm{NaAz}$ in PBS until ready for processing. Sections were than washed in PBS and incubated in blocking buffer ( $1 \%$ normal goat serum, $0.2 \%$ Triton $\mathrm{X}$ ) and incubated overnight at $4{ }^{\circ} \mathrm{C}$ with $1: 500$ chicken anti-GFP (Abcam ab13970) and rabbit anti-TH (1:500, Millipore, USA). GFP was visualized with Alexa-488-labeled goat anti-chicken and TH with Alexa-594-labeled goat anti-rabbit (both Molecular Probes, USA, 1:500). After washing in PBS, sections were mounted and embedded in FluorSave (Merck Millipore).

\section{Statistics}

Data were analyzed using Prism 6 (Graphpad Software). Where appropriate (ie, cocaine locomotion, sucrose selfadministration, and cocaine-induced reinstatement), the D2R knockdown group was compared with the control group using a two-way repeated measures ANOVA with cocaine dose or before/after surgery as within-subjects factor. Significant main effects were then followed up with Sidak's multiple comparison test. When two groups were compared at one time point (ie, D2 knockdown qPCR, cocaine selfadministration), a Student's t-test was used.

\section{RESULTS}

\section{Knockdown of the D2R}

To validate knockdown, a fusion construct of renilla-D2R cDNA was transfected into human embryonic kidney cells.
These cells where then transfected with one of four shRNA sequences targeted at D2R mRNA or a control sequence. The data were corrected for transfection efficiency based on a cotransfection with luciferase. We observed efficient knockdown in all cases (Figure 1a). On the basis of this and a pilot experiment that assessed cocaine-induced locomotor activity (data not shown), we selected sequence 2 for subsequent experiments. Knockdown of D2R mRNA was assessed by qPCR on VTA dissections from animals after completion of the sucrose or cocaine self-administration experiment $(n=25)$ (Figure $1 \mathrm{~b}-\mathrm{d})$. D2R and TH mRNA quantification was normalized to beta-actin mRNA. We observed no difference in $\mathrm{TH}$ expression $(\Delta \mathrm{CT}$ mean difference: $-0.145 \pm 0.269, \mathrm{t}=0.5411, \mathrm{df}=23, P=0.59)$ and an increase in $\triangle \mathrm{CT}$ value for $\mathrm{D} 2 \mathrm{R}$ in the $\mathrm{D} 2 \mathrm{R}$ knockdown group $(\triangle \mathrm{CT}$ mean difference: $1.00 \pm 0.272, \mathrm{t}=3.680, \mathrm{df}=23, P=0.001)$. This corresponds to $\pm 50 \%$ knockdown. We observed comparable knockdown in a cohort $(n=3)$ that was killed 4 weeks after surgery (Supplementary Figure 1). Efficient virus expression was validated using immunohistochemistry against TH and GFP (Figure 1e). GFP expression was confined to the VTA in all cases $(n=48)$.

\section{Cocaine-Induced Locomotor Activity}

We validated the knockdown behaviorally by determining cocaine-induced locomotor activity (Vanderschuren et al, 2000; Bello et al, 2011). We found that animals with D2R knockdown were hypersensitive to a low dose of cocaine $\left(\mathrm{F}_{(1,60) \text { knockdown }}=11.80, P=0.001\right)$ (Figure 2a). Animals with D2R knockdown showed an increase in locomotor activity after injection with both $5 \mathrm{mg} / \mathrm{kg}(\mathrm{t}=2.508, \mathrm{df}=60, P=0.044)$ and $10 \mathrm{mg} / \mathrm{kg}$ cocaine $(\mathrm{t}=2.509, \quad \mathrm{df}=60, \quad P=0.044)$. We observed a trend towards increase in locomotor activity after D2R knockdown during the 15-min habituation period $\left(\mathrm{F}_{(1,60) \text { knockdown }}=3.697, P=0.059\right)$ but there was no effect of D2R knockdown on locomotor activity following a saline injection $(\mathrm{t}=0.897, \mathrm{df}=60, P=0.754)$. The increase in locomotor activity started within $5 \mathrm{~min}$ after i.p. injection and lasted for at least $30 \mathrm{~min}$ (Figure $2 \mathrm{~b}-\mathrm{d}$ ).

\section{Sucrose Self-Administration}

To investigate the effect of VTA D2R knockdown on sucrose self-administration, rats $(n=23)$ were tested on FR and PR for sucrose before and after virus injection. We found an increase in FR responding in both groups after surgery $\left(F_{(1,19)}\right.$ surgery $\left.=32.58, P=0.0001\right)$, which may reflect increased sucrose appetite in older and therefore heavier animals. We did not observe a difference in FR responding between the groups $\left(\mathrm{F}_{(1,19) \text { knockdown }}=0.922, P=0.349\right.$; data from two animals were excluded because of a malfunctioning operant chamber) (Figure 3a). However, D2R knockdown animals made approximately twice as many responses under a $\mathrm{PR}$ schedule of reinforcement $\left(\mathrm{F}_{(1,21)}\right.$ surgery $\times$ knockdown $=8.929$, $P=0.007$ ) (Figure 3b). VTA D2R knockdown did not affect inactive lever presses $\left(\mathrm{F}_{(1,}, 21\right) \quad$ surgery $\times$ knockdown $=1.388$, $P=0.253$ ) (Figure 3c). Next, we assessed responding under extinction and sucrose-primed reinstatement. We did not observe a difference between the two groups, neither under extinction $\left(\mathrm{F}_{(1,21) \text { knockdown }}=0.0760, P=0.785\right)$ (Figure $3 \mathrm{~d}$ ) 

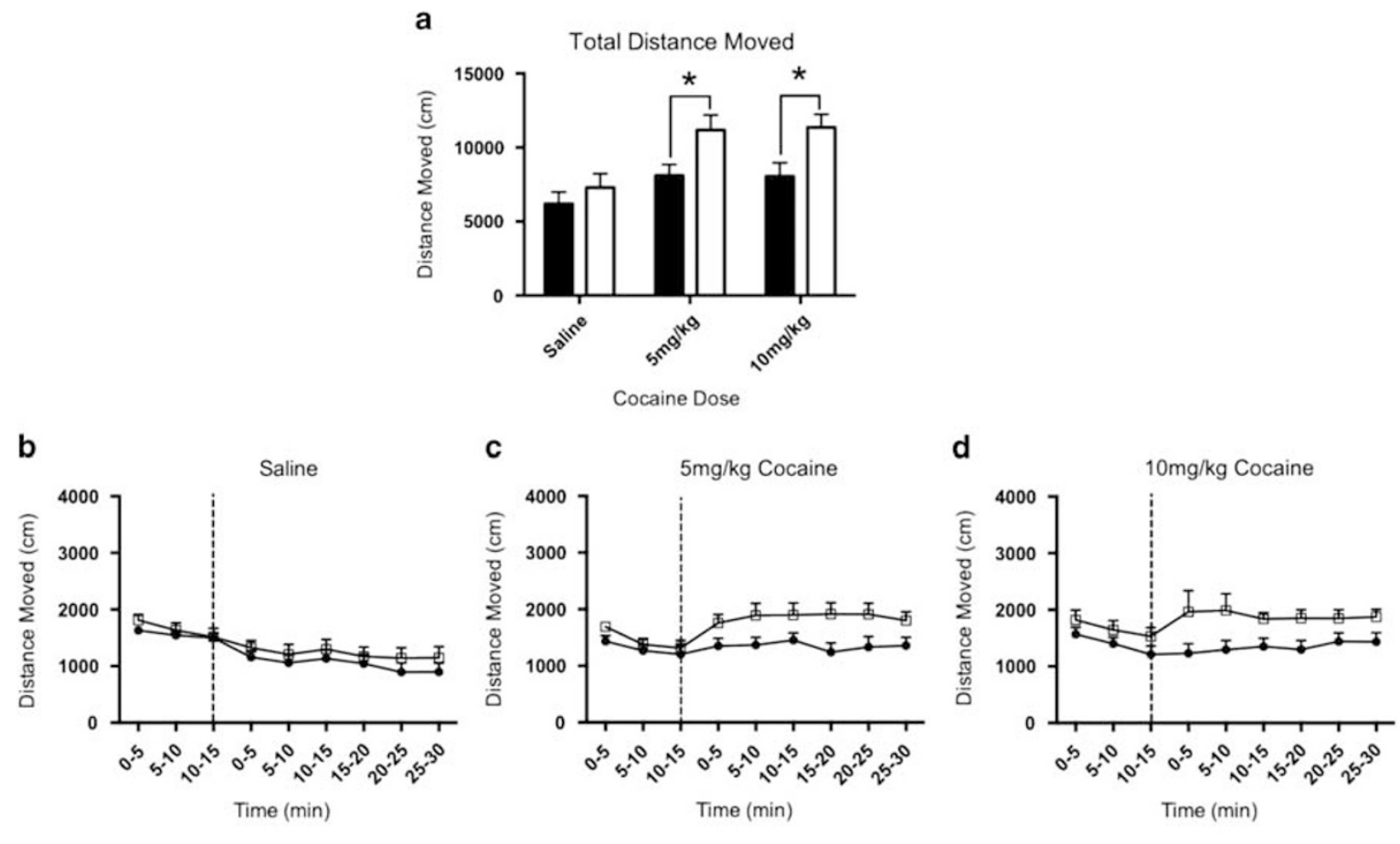

Control

D2R knockdown

Figure 2 D2R knockdown animals show an enhanced locomotor response to a low dose of cocaine. (a) Total distance moved in the 30 min following an injection with saline or cocaine. The same data are displayed in blocks of $5 \mathrm{~min}$ for saline (b), $5 \mathrm{mg} / \mathrm{kg}$ cocaine (c) or $10 \mathrm{mg} / \mathrm{kg}$ cocaine (d). Each session started with a I5-min habituation period, the end of which is indicated by the vertical dotted line. D2R-KD =D2R knockdown. Data represent means $+S E M * p<0.05$.

nor during sucrose-primed reinstatement $\left(\mathrm{F}_{(1,21)}\right.$ reinstatement $=$ 5.304, $P=0.032 ; \mathrm{F}_{(1,21) \text { knockdown }}=0.167, P=0.687$ ) (Figure $3 \mathrm{e}$ ).

\section{Cocaine Self-Administration}

We first tested the acquisition of cocaine self-administration during five sessions using a low unit dose of cocaine (ie, $0.083 \mathrm{mg}$ per infusion; Baarendse et al, 2014) (Figure 4a). During acquisition, we did not observe a difference between the two groups $\left(\mathrm{F}_{(1,19)}\right.$ knockdown $\left.=0.0137, P=0.908\right)$, nor did we observe a difference in responding for cocaine during the five subsequent FR1 sessions using our usual unit dose (ie, $0.25 \mathrm{mg}$ per infusion; (Veeneman et al, 2012a; 2012b; Baarendse et al, 2014) $\mathrm{t}=0.068, \mathrm{df}=35, P=0.95$ )(Figure 4b). There was also no difference between the groups in the loading dose of cocaine (ie, the initial amount of cocaine the animals take to bring their blood cocaine concentration up to a certain level at the beginning of the selfadministration session) (Supplementary Figure 2). However, the $\mathrm{D} 2 \mathrm{R}$ knockdown group made about twice as many active lever presses under a PR schedule of reinforcement $(\mathrm{t}=2.608, \mathrm{df}=28, P=0.014)$ (Figure $4 \mathrm{c})$.

\section{Conditioned Suppression of Cocaine Seeking}

In order to assess compulsive cocaine seeking, we employed a conditioned suppression model as previously used (Vanderschuren and Everitt, 2004). Figure 4d describes the total number of lever presses during presentation of the CS. We observed profound suppression of cocaine seeking during presentation of the footshock-associated CS, but no differences in responding between the groups $\left(\mathrm{F}_{(1,29)}\right.$ conditioning $=$ 31.03, $\quad P=0.001 ; \quad \mathrm{F}_{(1,29)} \quad$ knockdown $=2.691, \quad P=0.29$; $\mathrm{F}_{(1,29)}$ conditioning $\times$ knockdown $\left.=1.631, P=0.4112\right)($ Figure $4 \mathrm{~d})$.

\section{Reinstatement of Cocaine Seeking}

Significant cocaine-induced reinstatement was observed following injection of either $5 \mathrm{mg} / \mathrm{kg}$ or $10 \mathrm{mg} / \mathrm{kg}$ cocaine, but VTA D2R knockdown did not change reinstatement of cocaine seeking $\left(\mathrm{F}_{(2,50)}\right.$ cocaine dose $=9.90, \quad P=0.0002$; $\mathrm{F}_{(1,25)}$ knockdown $\left.=0.11 \quad P=0.738\right) \quad$ (Figure 4e). Responsecontingent presentation of the cocaine-associated cue-light in combination with retraction of the levers lead to reinstatement of cocaine-seeking, but there was no effect of VTA D2R knockdown $\left(\mathrm{F}_{(1,25)}\right.$ cue $=55.20, P<0.0001$; $\left.\mathrm{F}_{(1,25) \text { knockdown }}=0.001, P=0.980\right)$ (Figure $4 \mathrm{f}$ ).

\section{DISCUSSION}

Previous experiments have suggested that decreased D2R availability in the midbrain contributes to addiction-like behavior (Marinelli and White, 2000; Zald et al, 2008; Buckholtz et al, 2010; Bello et al, 2011; Madhavan et al, 2013). Moreover, obese mice have been shown to have desensitized D2 autoreceptors (Koyama et al, 2014). To investigate whether decreased expression of the D2R in the VTA promotes addictive behavior directed at food or drugs, we used shRNA-mediated knockdown of the D2R. VTA D2R knockdown increased the psychomotor response to a low dose of cocaine and increased the motivation to respond for 
a

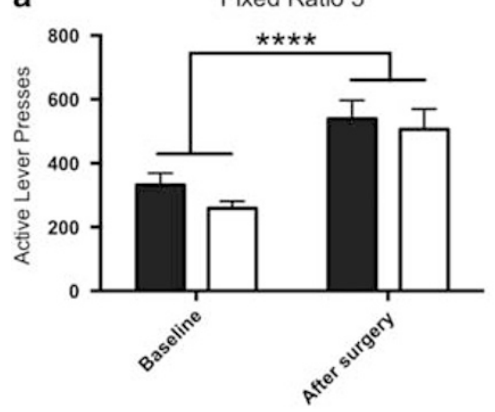

d

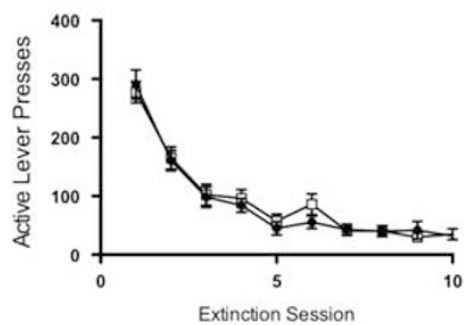

b

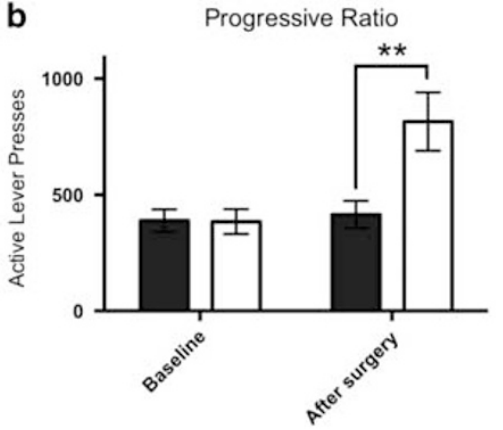

e

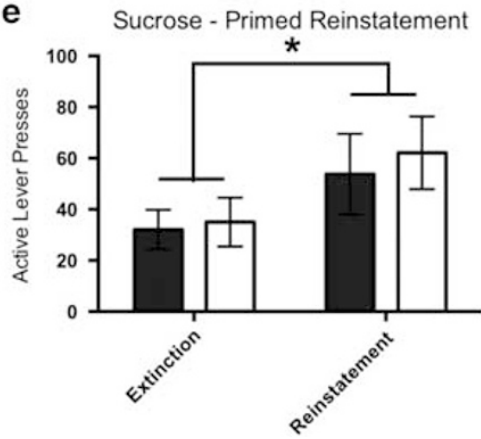

C Inactive Lever Presses

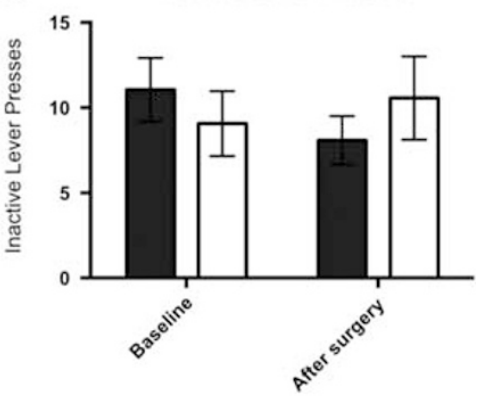

Control D2R knockdown

Figure 3 Sucrose self-administration under FR and PR schedules of reinforcement, extinction, and reinstatement. (a) FR5 responding (I h session) was increased after surgery with no difference between D2R knockdown and controls. (b) PR responding (average of six sessions) approximately doubled in D2R knockdown animals after surgery whereas PR responding in control animals was unaltered. (c) D2R knockdown and control animals made a comparable, minimal amount of inactive lever presses during PR sessions. There was no difference between experimental groups. (d) Rats were exposed to I0 (I h) extinction sessions, in which active lever presses were not reinforced. Extinction of responding occurred in a comparable manner in D2R knockdown and control animals. (e) The non-contingent delivery of three sucrose pellets induced significant reinstatement of sucrose seeking in both groups. 'Extinction' represents the number of active lever presses in extinction session 10. Data are presented as means+SEM $* p<0.05, * * p<0.01, * * * * p<0.000$ I.

sucrose or cocaine. However, there were no differences in sucrose or cocaine self-administration under a FR schedule of reinforcement, conditioned suppression of cocaine seeking, or reinstatement of sucrose or cocaine seeking. These data show that VTA D2R downregulation renders animals more motivated to work for a reward, but that other aspects of addictive behavior are not affected. A caveat of this study is that D2R knockdown was assessed by quantifying D2R mRNA expression 4 weeks after virus injection (Supplementary Figure 1) and at the end of the study (Figure 1). Clearly, mRNA expression is only an indirect measure of D2R function. Furthermore, two of the behavioral experiments (ie, responding for sucrose under a PR schedule of reinforcement, acquisition of cocaine self-administration) were performed 2 weeks after virus injection. Although behavioral effects of gene expression knockdown in the brain have been demonstrated within days after virus injection (eg, Tung et al, 2010), we cannot completely exclude that the increase in responding for sucrose under a PR schedule was caused by an off-target effect of the D2R knockdown vector, or that the lack of an effect on the acquisition of cocaine selfadministration was the result of insufficient D2R knockdown. The results should be interpreted with this limitation in mind.

Downregulation of VTA D2R increased the psychomotor response to a low dose of cocaine. This is in accordance with previous work, in which the D2R was ablated in all DA neurons (Bello et al, 2011). Cocaine increases the synaptic DA concentration by blocking the DA transporter (Ritz and Kuhar, 1989) and in turn, DA inhibits firing of DA neurons by binding to the somatodendritic D2R (Zhou et al, 2006). Decreased D2R expression on DA neurons is therefore likely to impair this feedback mechanism, providing a plausible explanation for our results. Indeed, it has previously been shown that decreased D2R autoreceptor activity or Drd 2 knockout in DA neurons results in increased DA release in the striatum as assessed with fast scan cyclic voltammetry (Bello et al, 2011; Calipari et al, 2014b). Importantly, psychostimulant drugs evoke stereotyped behavior at higher doses than those that induce psychomotor hyperactivity (Sahakian et al, 1975; Kuczenski et al, 1991; Flagel and Robinson, 2007), but only at very high doses of cocaine (typically at $30 \mathrm{mg} / \mathrm{kg}$ and higher) does stereotyped behavior interfere with the expression of psychomotor activity. Interestingly, we observed in pilot experiments that after treatment with cocaine doses $>15 \mathrm{mg} / \mathrm{kg}$, horizontal locomotor activity was reduced in D2R knockdown animals compared with controls, which may be the result of an increase in stereotyped behavior. We chose not to include these data in the manuscript, however, because our test setup measures horizontal locomotion, so any referral to stereotyped behavior would be speculative. Interestingly, we did not find a change in locomotor activity after a saline injection, or in inactive lever presses in the self-administration experiments. This result diverges from the findings with Drd2 autoreceptor knockout mice, which did show 
a

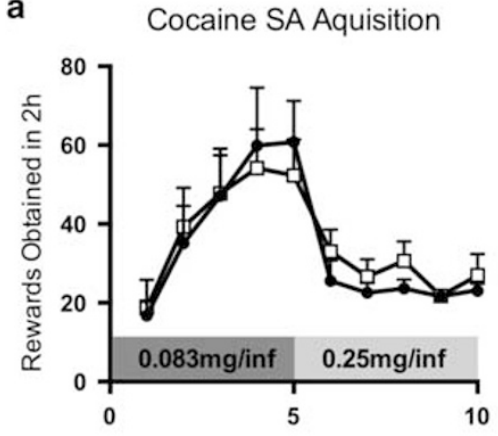

d

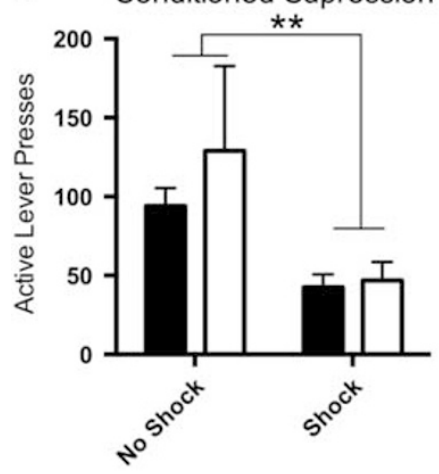

b

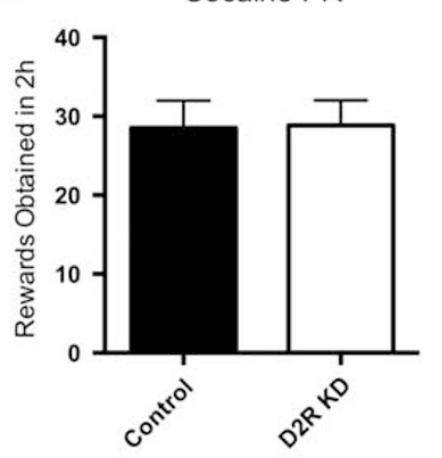

e

e

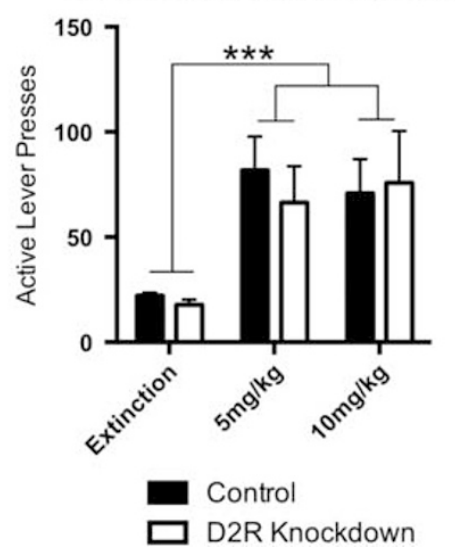

c

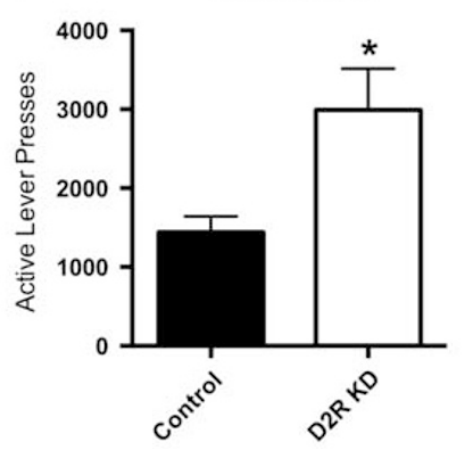

$\mathbf{f}$
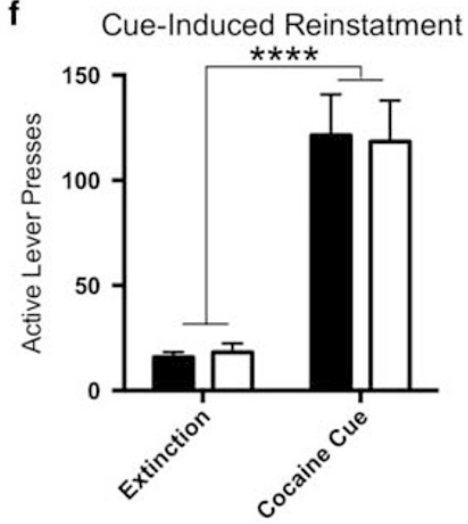

Figure 4 Cocaine self-administration under FR and PR schedules of reinforcement, conditioned suppression, extinction, and reinstatement. (a) Rats acquired cocaine self-administration using a unit dose of $0.083 \mathrm{mg}$ per infusion for five sessions, followed by five sessions in which $0.25 \mathrm{mg}$ per infusion was available. Acquisition of cocaine self-administration was not altered by VTA D2R knockdown. (b) Cocaine intake as assessed under a FRI schedule (2 $\mathrm{h}$ session) did not differ between the groups. The data represent the average cocaine intake during session 6-10 in Figure 4a. (c) When tested under a PR schedule (average of three sessions), D2R knockdown animals made significantly more active lever presses. (d) Cocaine seeking was suppressed by the presentation of a footshock-associated CS. There was no difference in the magnitude of suppression between control and D2R knockdown animals. Data represent the total number of lever presses during CS presentation. (e) Cocaine-primed reinstatement of cocaine seeking. Both 5 and I0 mg/kg cocaine induced significant reinstatement of responding in both experimental groups. ( $f$ ) Cue-induced reinstatement. Presentation of the cocaine-paired cues induced reinstatement in both groups. All reinstatement sessions lasted I h. D2R-KD $=\mathrm{D} 2 \mathrm{R}$ knockdown. Data represent group means $+S E M * p<0.05, * * 2<0.0$ I, ***** $p<0.001$, ******** $p<0.0001$.

increased basal locomotor activity (Bello et al, 2011). Apart from the species difference, the different findings may be explained by the location of the knockdown, which, in our case, was confined to the VTA. Thus, the effects of Bello et al may be the result of the absence of the D2R in the substantia nigra, which is known to play a role in novelty-induced exploration (Schiemann et al, 2012). Alternatively, in our study, knockdown resulted in a 50\% reduction in $\mathrm{D} 2 \mathrm{R}$ expression, which is likely to evoke more modest behavioral effects than a complete knockout of D2R. We would also like to emphasize that in our study, the D2R knockdown was induced in adult animals, whereas in the study of Bello et al (2011), the Drd2 gene was constitutively absent throughout the development of the animals, which may also have induced compensatory functional changes. A limitation of the current approach is that the vector used does not selectively transfect dopamine neurons, but other neuron types as well. Although they form a minority, there are GABAergic neurons in the VTA that are responsive to a D2R agonist (Margolis et al, 2006), and project to, eg, the PFC, amygdala, and NAcc (Swanson, 1982; Margolis et al, 2008).
Likewise, there are glutamatergic neurons that are sensitive to a D2R agonist in the medial VTA (Hnasko et al, 2012). Although a contribution of VTA GABAergic or glutamatergic neurons to the behavioral changes observed could therefore not be excluded, the available literature strongly suggests a role for VTA DA, as described below. We observed that downregulation of the D2R in the VTA results in increased motivation to respond for both sucrose and cocaine without changing responding under a FR schedule of reinforcement. This is consistent with the well-established notion that mesolimbic DA mediates incentive motivation and willingness to work for rewards, especially when the effort requirement is high (Salamone and Correa, 2012). The striking difference in how FR responding (which may be more related to reward intake than to incentive motivation) and PR responding (widely accepted as an index of incentive motivation) are affected by VTA D2R knockdown fits well into a large literature that shows markedly different neural substrates of reward consumption $v s$ processes related to motivation and willingness to perform effort (Berridge et al, 2009), whereby DA has been primarily implicated in the 
latter (Barbano and Cador, 2007). As we hypothesized that DA release in the NAcc will be increased by VTA D2R knockdown, this might well explain the increased willingness that the animals show to obtain a sucrose or cocaine reward.

We did not find a change in conditioned suppression of cocaine seeking, nor did we find differences in food-, cocaine-, or cue-induced reinstatement after VTA D2R knockdown. Thus, decreased VTA D2R activity specifically increased incentive motivation, but does not alter other addiction-like behaviors such as compulsive seeking or reinstatement. Interestingly, it has previously been shown that lengthening daily cocaine access ( $6 \mathrm{~h}$ per day) results in escalated cocaine intake, which is interpreted as a sign of addiction-like behavior (Ahmed and Koob, 1998; 1999,; Edwards and Koob, 2013). In our study, cocaine intake was not increased in the $\mathrm{D} 2 \mathrm{R}$ knockdown group, which is in accordance with the observations that escalation of cocaine self-administration is associated with a decrease in DA release in the ventral striatum (Calipari et al, 2014a; Willuhn et al, 2014). In this regard, the initial reinforcing effects of cocaine are thought to be mediated by the ventral striatum, whereas the development of habitual and finally compulsive cocaine intake is associated with functional changes in the dorsal striatum and prefrontal cortex (Jentsch and Taylor, 1999; Everitt and Robbins, 2005; Pierce and Vanderschuren, 2010; Goldstein and Volkow, 2011; Lesscher and Vanderschuren, 2012). It is therefore likely that our manipulation predominantly altered VTA to ventral striatal DA signaling and therefore only influenced the incentive motivational properties of sucrose and cocaine, but did not directly promote other aspects of addiction-like behavior. Of course, even though VTA D2R knockdown did not result in the emergence of multiple signs of addiction-like behavior, this does not exclude a role for VTA D2R in the development of addiction. Humans or animals more motivated for drugs may overcome bigger hurdles to obtain them and thus expose themselves to more drugs over time, which may ultimately lead to full-blown addictive behavior, mediated by other mechanisms than VTA D2R function. Likewise, increased motivation for food may promote increased body weight and obesity in the long run, even without being labeled 'food addiction'. In conclusion, we show that decreased availability of the D2R in the VTA specifically induces increased motivation for both food and drug rewards.

\section{FUNDING AND DISCLOSURE}

The work was supported by the NeuroFAST consortium (the integrated neurobiology of food intake, addiction, and stress). NeuroFAST is funded by the European Union Seventh Framework Programme (FP7/2007-2013) under grant agreement $\mathrm{n}^{\circ} 245009$.

\section{REFERENCES}

Aghajanian GK, Bunney BS (1977). Dopamine“autoreceptors": pharmacological characterization by microiontophoretic single cell recording studies. Naunyn Schmiedebergs Arch Pharmacol 297: $1-7$.
Ahmed SH, Koob GF (1998). Transition from moderate to excessive drug intake: change in hedonic set point. Science 282: 298-300.

Ahmed SH, Koob GF (1999). Long-lasting increase in the set point for cocaine self-administration after escalation in rats. Psychopharmacology (Berl) 146: 303-312.

Anzalone A, Lizardi-Ortiz JE, Ramos M, De Mei C, Hopf FW, Iaccarino C et al (2012). Dual control of dopamine synthesis and release by presynaptic and postsynaptic dopamine D2 receptors. J Neurosci 32: 9023-9034.

Baarendse PJ, Limpens JH, Vanderschuren LJ (2014). Disrupted social development enhances the motivation for cocaine in rats. Psychopharmacology (Berl) 231: 1695-1704.

Baik J-H (2013). Dopamine signaling in food addiction: role of dopamine D2 receptors. BMB Rep 46: 519-526.

Barbano MF, Cador M (2007). Opioids for hedonic experience and dopamine to get ready for it. Psychopharmacology (Berl) 191: 497-506.

Bello EP, Mateo Y, Gelman DM, Noaín D, Shin JH, Low MJ et al (2011). Cocaine supersensitivity and enhanced motivation for reward in mice lacking dopamine D2 autoreceptors. Nat Neurosci 14: 1033-1038.

Berridge KC, Robinson TE, Aldridge JW (2009). Dissecting components of reward: 'liking', "wanting," and learning. Curr Opin Pharmacol 9: 65-73.

Buckholtz JW, Treadway MT, Cowan RL, Woodward ND, Li R, Ansari MS et al (2010). Dopaminergic network differences in human impulsivity. Science 329: 532.

Calipari ES, Ferris MJ, Jones SR (2014a). Extended access of cocaine self-administration results in tolerance to the dopamine-elevating and locomotor-stimulating effects of cocaine. J Neurochem 128: 224-232.

Calipari ES, Sun H, Eldeeb K, Luessen DJ, Feng X, Howlett AC et al (2014b). Amphetamine self-administration attenuates dopamine D2 autoreceptor function. Neuropsychopharmacology 39: $1833-1842$.

de Weijer BA, van de Giessen E, van Amelsvoort TA, Boot E, Braak B, Janssen IM et al (2011). Lower striatal dopamine D2/3 receptor availability in obese compared with non-obese subjects. EJNMMI Res 1: 37.

Deroche-Gamonet V, Belin D, Piazza PV (2004). Evidence for addiction-like behavior in the rat. Science 305: 1014-1017.

Di Chiara G, Imperato A (1988). Drugs abused by humans preferentially increase synaptic dopamine concentrations in the mesolimbic system of freely moving rats. Proc Natl Acad Sci USA 85: 5274-5278.

Du G, Yonekubo J, Zeng Y, Osisami M, Frohman MA (2006). Design of expression vectors for RNA interference based on miRNAs and RNA splicing. FEBS J 273: 5421-5427.

Edwards S, Koob GF (2013). Escalation of drug self-administration as a hallmark of persistent addiction liability. Behav Pharmacol 24: $356-362$

Effertz T, Mann K (2013). The burden and cost of disorders of the brain in Europe with the inclusion of harmful alcohol use and nicotine addiction. Eur Neuropsychopharmacol 23: 742-748.

Eisenstein SA, Antenor-Dorsey JAV, Gredysa DM, Koller JM, Bihun EC, Ranck SA et al (2013). A comparison of D2 receptor specific binding in obese and normal-weight individuals using PET with (N-[(11)C]methyl)benperidol. Synapse 67: 748-756.

European Commission (2007). White Paper. A Strategy for Europe on Nutrition, Overweight and Obesity related health issues.

Everitt BJ, Robbins TW (2005). Neural systems of reinforcement for drug addiction: from actions to habits to compulsion. Nat Neurosci 8: 1481-1489.

Flagel SB, Robinson TE (2007). Quantifying the psychomotor activating effects of cocaine in the rat. Behav Pharmacol 18: 297-302.

Flegal KM, Carroll MD, Ogden CL, Curtin LR (2010). Prevalence and trends in obesity among US adults, 1999-2008. JAMA 303: 235-241. 
Gearhardt A, Corbin W (2009). Food addiction: an examination of the diagnostic criteria for dependence. J Addict 3: 1-7.

Gearhardt AN, Boswell RG, White MA (2014). The association of "food addiction" with disordered eating and body mass index. Eat Behav 15: 427-433.

Goldstein RZ, Volkow ND (2011). Dysfunction of the prefrontal cortex in addiction: neuroimaging findings and clinical implications. Nat Rev Neurosci 12: 652-669.

Gustavsson A, Svensson M, Jacobi F, Allgulander C, Alonso J, Beghi E et al (2011). Cost of disorders of the brain in Europe 2010. Eur Neuropsychopharmacol 21: 718-779.

Henry DJ, Greene MA, White FJ (1989). Electrophysiological effects of cocaine in the mesoaccumbens dopamine system: repeated administration. J Pharmacol Exp Ther 251: 833-839.

Hnasko TS, Hjelmstad GO, Fields HL, Edwards RH (2012). Ventral tegmental area glutamate neurons: electrophysiological properties and projections. J Neurosci 32: 15076-15085.

Isomura Y, Harukuni R, Takekawa T, Aizawa H, Fukai T (2009). Microcircuitry coordination of cortical motor information in selfinitiation of voluntary movements. Nat Neurosci 12: 1586-1593.

Jentsch JD, Taylor JR (1999). Impulsivity resulting from frontostriatal dysfunction in drug abuse: implications for the control of behavior by reward-related stimuli. Psychopharmacology (Berl) 146: 373-390.

Jupp B, Dalley JW (2014). Behavioral endophenotypes of drug addiction: Etiological insights from neuroimaging studies. Neuropharmacology 76 Pt B: 487-497.

Kessler RC, Berglund PA, Chiu WT, Deitz AC, Hudson JI, Shahly V et al (2013). The prevalence and correlates of binge eating disorder in the World Health Organization World Mental Health Surveys. Biol Psychiatry 73: 904-914.

Koyama S, Mori M, Kanamaru S, Sazawa T, Miyazaki A, Terai H et al (2014). Obesity attenuates D2 autoreceptor-mediated inhibition of putative ventral tegmental area dopaminergic neurons. Physiol Rep 2: e12004.

Kuczenski R, Segal DS, Aizenstein ML (1991). Amphetamine, cocaine, and fencamfamine: relationship between locomotor and stereotypy response profiles and caudate and accumbens dopamine dynamics. J Neurosci 11: 2703-2712.

la Fleur SE, Vanderschuren LJ, Luijendijk MC, Kloeze BM, Tiesjema B, Adan RA (2007). A reciprocal interaction between food-motivated behavior and diet-induced obesity. Int $J$ Obes (Lond) 31: 1286-1294.

Lesscher HM, Vanderschuren LJ (2012). Compulsive drug use and its neural substrates. Rev Neurosci 23: 731-745.

Limpens JH, Schut EH, Voorn P, Vanderschuren LJ (2014). Using conditioned suppression to investigate compulsive drug seeking in rats. Drug Alcohol Depend 142: 314-324.

Madhavan A, Argilli E, Bonci A, Whistler JL (2013). Loss of d2 dopamine receptor function modulates cocaine-induced glutamatergic synaptic potentiation in the ventral tegmental area. Journal of Neuroscience 33: 12329-12336.

Margolis EB, Lock H, Hjelmstad GO, Fields HL (2006). The ventral tegmental area revisited: is there an electrophysiological marker for dopaminergic neurons? J Physiol 577: 907-924.

Margolis EB, Mitchell JM, Ishikawa J, Hjelmstad GO, Fields HL (2008). Midbrain dopamine neurons: projection target determines action potential duration and dopamine $\mathrm{D}(2)$ receptor inhibition. I Neurosci 28: 8908-8913.

Marinelli M, White FJ (2000). Enhanced vulnerability to cocaine self-administration is associated with elevated impulse activity of midbrain dopamine neurons. J Neurosci 20: 8876-8885.

Meye FJ, Adan RA (2014). Feelings about food: the ventral tegmental area in food reward and emotional eating. Trends Pharmacol Sci 35: 31-40.

Nederkoorn C, Jansen E, Mulkens S, Jansen A (2007). Impulsivity predicts treatment outcome in obese children. Behav Res Ther 45: $1071-1075$
Nestler EJ (2005). Is there a common molecular pathway for addiction? Nat Neurosci 8: 1445-1449.

Olmstead MC, Parkinson JA, Miles FJ, Everitt BJ, Dickinson A (2000). Cocaine-seeking by rats: regulation, reinforcement and activation. Psychopharmacology (Berl) 152: 123-131.

Pierce RC, Vanderschuren LJ (2010). Kicking the habit: the neural basis of ingrained behaviors in cocaine addiction. Neurosci Biobehav Rev 35: 212-219.

Potenza MN (2014). Obesity, food, and addiction: emerging neuroscience and clinical and public health implications. Neuropsychopharmacology 39: 249-250.

Richardson NR, Roberts DC (1996). Progressive ratio schedules in drug self-administration studies in rats: a method to evaluate reinforcing efficacy. J Neurosci Methods 66: 1-11.

Ritz MC, Kuhar MJ (1989). Relationship between selfadministration of amphetamine and monoamine receptors in brain: comparison with cocaine. J Pharmacol Exp Ther 248: 1010-1017.

Robinson TE, Berridge KC (1993). The neural basis of drug craving: an incentive-sensitization theory of addiction. Brain Res Brain Res Rev 18: 247-291.

Sahakian BJ, Robbins TW, Morgan MJ, Iversen SD (1975). The effects of psychomotor stimulants on stereotypy and locomotor activity in socially-deprived and control rats. Brain Res 84: 195-205.

Salamone JD, Correa M (2012). The mysterious motivational functions of mesolimbic dopamine. Neuron 76: 470-485.

Salamone JD, Correa M, Farrar AM, Nunes EJ, Pardo M (2009). Dopamine, behavioral economics, and effort. Front Behav Neurosci 3: 13

Schiemann J, Schlaudraff F, Klose V, Bingmer M, Seino S, Magill PJ et al (2012). K-ATP channels in dopamine substantia nigra neurons control bursting and novelty-induced exploration. Nat Neurosci 15: 1272-1280.

Sibley DR, Monsma FJ Jr (1992). Molecular biology of dopamine receptors. Trends Pharmacol Sci 13: 61-69.

Swanson LW (1982). The projections of the ventral tegmental area and adjacent regions: a combined fluorescent retrograde tracer and immunofluorescence study in the rat. Brain Res Bull 9: 321-353.

Tepper JM, Sun BC, Martin LP, Creese I (1997). Functional roles of dopamine D2 and D3 autoreceptors on nigrostriatal neurons analyzed by antisense knockdown in vivo. I Neurosci 17: 2519-2530.

Tournier BB, Steimer T, Millet P, Moulin-Sallanon M, Vallet P, Ibañez V et al (2013). Innately low D2 receptor availability is associated with high novelty-seeking and enhanced behavioural sensitization to amphetamine. Int J Neuropsychopharmacol 16: 1819-1834.

Tung YC, Ayuso E, Shan X, Bosch F, O'Rahilly S, Coll AP et al (2010). Hypothalamic-specific manipulation of Fto, the ortholog of the human obesity gene FTO, affects food intake in rats. PLoS ONE 5: e8771.

United Nations Office on Drugs and Crime (2012). World Drug Report 2012. unodcorg at <http://www.unodc.org/documents/ data-and-analysis/WDR2012/WDR_2012_web_small.pdf $>$.

Usiello A, Baik JH, Rougé-Pont F, Picetti R, Dierich A, LeMeur M et al (2000). Distinct functions of the two isoforms of dopamine D2 receptors. Nature 408: 199-203.

van Gestel MA, van Erp S, Sanders LE, Brans MA, Luijendijk MC, Merkestein $M$ et al (2014). shRNA-induced saturation of the microRNA pathway in the rat brain. Gene Ther 21: 205-211.

Vanderschuren LJ, Schoffelmeer AN, Wardeh G, De Vries TJ (2000). Dissociable effects of the kappa-opioid receptor agonists bremazocine, U69593, and U50488H on locomotor activity and long-term behavioral sensitization induced by amphetamine and cocaine. Psychopharmacology (Berl) 150: 35-44. 
Vanderschuren LJ, Everitt BJ (2004). Drug seeking becomes compulsive after prolonged cocaine self-administration. Science 305: 1017-1019.

Veeneman MM, Boleij H, Broekhoven MH, Snoeren EM, Guitart Masip M, Cousijn J et al (2011). Dissociable roles of mGlu5 and dopamine receptors in the rewarding and sensitizing properties of morphine and cocaine. Psychopharmacology (Berl) 214: 863-876.

Veeneman MM, Broekhoven MH, Damsteegt R, Vanderschuren LJ (2012a). Distinct contributions of dopamine in the dorsolateral striatum and nucleus accumbens shell to the reinforcing properties of cocaine. Neuropsychopharmacology 37: 487-498.

Veeneman $\mathrm{MM}$, van Ast $\mathrm{M}$, Broekhoven $\mathrm{MH}$, Limpens $\mathrm{JH}$, Vanderschuren LJ (2012b). Seeking-taking chain schedules of cocaine and sucrose self-administration: effects of reward size, reward omission, and $\alpha$-flupenthixol. Psychopharmacology (Berl) 220: 771-785.

Volkow ND, Wang GJ, Tomasi D, Baler RD (2013). The addictive dimensionality of obesity. Biol Psychiatry 73: 811-818.

Volkow ND, Wang GJ, Fowler JS, Tomasi D (2011). Addiction circuitry in the human brain. Annu Rev Pharmacol Toxicol 52: 321-336.

Wang G-JJ, Volkow ND, Logan J, Pappas NR, Wong CT, Zhu W et al (2001). Brain dopamine and obesity. Lancet 357: 354-357.

White MD, Milne RV, Nolan MF (2011). A molecular toolbox for rapid generation of viral vectors to up- or down-regulate neuronal gene expression in vivo. Front Mol Neurosci 4: 8.
Willuhn I, Burgeno LM, Groblewski PA, Phillips PE (2014). Excessive cocaine use results from decreased phasic dopamine signaling in the striatum. Nat Neurosci 17: 704-709.

Xue Y, Steketee JD, Rebec GV, Sun W (2011). Activation of $\mathrm{D}_{2}$-like receptors in rat ventral tegmental area inhibits cocaine-reinstated drug-seeking behavior. Eur J Neurosci 33: 1291-1298.

Zald DH, Cowan RL, Riccardi P, Baldwin RM, Ansari MS, Li R et al (2008). Midbrain dopamine receptor availability is inversely associated with novelty-seeking traits in humans. J Neurosci 28: 14372-14378.

Zhou Y, Bunney BS, Shi WX (2006). Differential effects of cocaine on firing rate and pattern of dopamine neurons: role of alphal receptors and comparison with L-dopa and apomorphine. J Pharmacol Exp Ther 317: 196-201.

(i) (2) (2) This work is licensed under a Creative Commons Attribution-NonCommercial-ShareAlike 4.0 International License. The images or other third party material in this article are included in the article's Creative Commons license, unless indicated otherwise in the credit line; if the material is not included under the Creative Commons license, users will need to obtain permission from the license holder to reproduce the material. To view a copy of this license, visit http:// creativecommons.org/licenses/by-nc-sa/4.0/

Supplementary Information accompanies the paper on the Neuropsychopharmacology website (http://www.nature.com/npp) 